\title{
The syndemic challenge of tuberculosis and tobacco use
}

\author{
Kamran Siddiqi', Thomas E. Novotny ${ }^{2}$
}

The term 'syndemic' describes linked health problems involving two or more conditions that act synergistically, causing an excess burden of disease in the population. These interacting conditions often cluster similarly by person, place, and time. Most importantly, interventions against them must address the underlying conditions that bind the problems together ${ }^{1}$. The global incidence of tuberculosis (TB) has declined over the last few decades, albeit far slower than envisioned by the World Health Organization (WHO). For 2018-2019, TB incidence only declined by $2.3 \%$, suggesting that WHO objectives for 2030 will not be met $^{2}$. Ten million persons were infected in 2019 , but the burden of TB disease is highest in low- and middle-income countries (LMICs), where 95\% of TB deaths occur. The high TB burden countries include India, Indonesia, China, Philippines, and Bangladesh, and these nations also rank among the top ten countries for daily smoking prevalence ${ }^{3}$. Poverty, poor nutrition, and lack of comprehensive healthcare systems in these nations play into the TB and smoking syndemic.

Smoking and secondhand smoke exposure are two of several conditions that exacerbate adverse TB outcomes such as recurrent disease, excess mortality, and treatment failure. These conditions include diabetes, poor nutrition, alcohol use, and HIV infection. Because there are over one billion smokers globally, it is not surprising that $17.6 \%$ (95\% CI: 8.4-21.4) of new cases and $15.2 \%$ (95\% CI: 1.8-31.9) of TB deaths are attributable to smoking in high burden countries, regardless of other risk factors ${ }^{4}$.

Given the syndemicity of TB and tobacco use, we might ask what would happen if the smoking prevalence among those infected with TB could be effectively reduced through consistent, integrated treatment for tobacco use. Unfortunately, and despite a higher prevalence of smoking in TB patients compared to the general population ${ }^{5}$, the vast majority of TB patients are neither routinely asked about their smoking status nor advised to quit ${ }^{6}$.

Some progress has been made to meet the syndemic challenge of TB and smoking. There has been increased interest in policies to help TB patients quit smoking $^{7}$ as well as recognition of the need for evidence-based smoking cessation interventions ${ }^{8}$. The $\mathrm{WHO}$ and the Union were first to embrace this challenge in the 2007 Monograph on TB and Tobacco Control, which called for further research and the application of cessation assistance in TB programs. There are also a few large randomized-controlled trials (RCTs $)^{8,10}$ conducted in high-TB burden countries, which highlight that face-to-face behavioral interventions can achieve high quit rates among TB patients ${ }^{8}$. Those who quit smoking were shown to have better overall clinical outcomes. In these studies, TB staff were able to deliver behavioral interventions for smoking cessation. However, because of several health system barriers $^{11}$ (e.g. cost, reach, sustainability), no high-TB burden country has so far integrated consistent face-to-face behavioral interventions for smoking cessation within its TB services. Recognizing the challenges of integrating and scaling

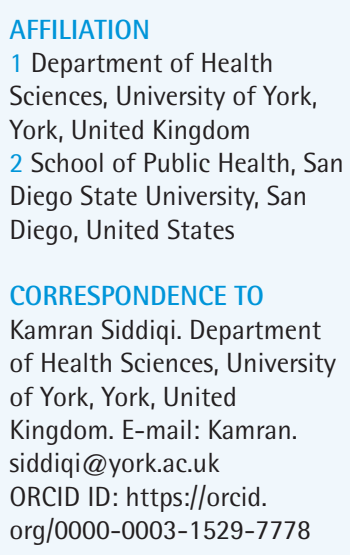

CORRESPONDENCE TO Kamran Siddiqi. Department of Health Sciences, University of York, York, United Kingdom. E-mail: Kamran. siddiqi@york.ac.uk ORCID ID: https://orcid. org/0000-0003-1529-7778

KEYWORDS syndemic, tuberculosis, tobacco

Received: 15 February 2021 Accepted: 21 February 2021 
up face-to-face interventions, WHO has developed a smoking cessation package (mTB-Tobacco) that can be delivered as mobile phone messages to TB patients $^{12}$.

The evidence so far points towards a strong syndemic association between adverse TB outcomes and tobacco use. The evidence is also emerging in support of face-to-face behavioral interventions that can be delivered within health services in high-TB burden countries. On the upcoming World TB Day, we want to emphasize the important contribution of tobacco use in sustaining the TB disease burden and to appeal to policymakers and practitioners in highTB burden countries that they recognize tobacco cessation as an important part of our efforts to end the global TB epidemic.

\section{REFERENCES}

1. Merrill S. Introducing Syndemics: A Critical Systems Approach to Public and Community Health. San Fracisco: Jossey-Bass. 2009;304.

2. World Health Organization. [Global tuberculosis report 2020: executive summary]. World Health Organization; 2020. Accessed February 15, 2021. https://apps.who.int/ iris/bitstream/handle/10665/337538/9789240016941ara.pdf

3. Drope J, Schluger N, Cahn Z, et al. The Tobacco Atlas. American Cancer Society, Vital Strategies; 2018:21-22. Accessed February 15, 2021. https://tobaccoatlas.org/ wp-content/uploads/2018/03/TobaccoAtlas_6thEdition_ LoRes_Rev0318.pdf

4. Amere GA, Nayak P, Salindri AD, Narayan KMV, Magee MJ. Contribution of Smoking to Tuberculosis Incidence and Mortality in High-Tuberculosis-Burden Countries. Am J Epidemiol. 2018;187:1846-1855. doi:10.1093/aje/kwy081

5. Marshall AM, Barua D, Mitchell A, et al. Smoking prevalence among tuberculosis patients: A crosssectional study in Bangladesh and Pakistan. Tob Induc Dis. 2020;18:70. doi:10.18332/tid/125452

6. Warsi S, Elsey H, Boeckmann M, et al. Using behaviour change theory to train health workers on tobacco cessation support for tuberculosis patients: a mixed-methods study in Bangladesh, Nepal and Pakistan. BMC Health Serv Res. 2019;19(1):71. doi:10.1186/s12913-019-3909-4

7. United Nations Development Programme. Integrating Tobacco Control into Tuberculosis and HIV Responses. September 25, 2018. Accessed September 26, 2019. https://www.undp.org/content/undp/en/home/ librarypage/hiv-aids/integrating-tobacco-control-intotuberculosis-and-hiv-responses.html

8. Siddiqi K, Khan A, Ahmad M, et al. Action to Stop Smoking In Suspected Tuberculosis (ASSIST) in Pakistan: a Cluster Randomized, Controlled Trial. Ann Intern Med. 2013;158(9):667-675. doi:10.7326/0003-4819-158-9-201305070-00006

9. World Health Organization, International Union Against Tuberculosis and Lung Disease. A WHO/ The Union monograph on TB and Tobacco Control: Joining efforts to control two related global epidemics. World Health Organization; 2007. Accessed February 15, 2021. https://apps.who.int/iris/bitstream/ handle/10665/43812/9789241596220_eng. pdf? sequence $=1 \&$ isAllowed $=y$

10. Dogar OF, Keding A, Gabe R, et al. Cytisine for smoking cessation in patients with tuberculosis: a multicentre, randomised, double-blind, placebo-controlled phase 3 trial. Lancet Public Health. 2020;8(11). doi:10.1016/S2214-109X(20)30312-0

11. Dogar O, Elsey H, Khanal S, Siddiqi K. Challenges of Integrating Tobacco Cessation Interventions in TB Programmes: Case Studies from Nepal and Pakistan. J Smok Cessat. 2016;11(2):108-115. doi:10.1017/jsc.2015.20

12. World Health Organization, International Telecommunication Union. Be He@lthy, Be Mobile: A handbook on how to implement mTB-Tobacco. World Health Organization, International Telecommunication Union; 2019. Accessed February 15, 2021. https://apps.who.int/iris/bitstream/ha ndle/10665/325243/9789241515900-eng.pdf

CONFLICTS OF INTEREST

The authors have each completed and submitted an ICMJE form for disclosure of potential conflicts of interest. The authors declare that they have no competing interests, financial or otherwise, related to the current work. K. Siddiqi reports grants from European Commission, and non-financial support from Aflofarm, during the conduct of the study.

\section{FUNDING}

There was no source of funding for this research.

PROVENANCE AND PEER REVIEW

Commissioned; internally peer reviewed. 